approach may be more efficient under certain circumstances. In randomised trials, however, both approaches can be assumed to provide the same underlying intervention effects if the trials are adequately randomised: the difference in mean endpoint scores will be the same on average as the difference in mean change scores. To our knowledge, the decision for using one measure over another is currently not resolved, with evidence suggesting that endpoint scores tend to produce more conservative estimates. ${ }^{3}$ Cella \& Preti further suggested applying a restricted maximum likelihood estimation method to the meta-analysis. Research synthesis methodology is a developing field and there is no consensus at present on the best approach for random-effects meta-analysis. Although valuable alternatives to random-effects estimation methods have been developed, ${ }^{4}$ DerSimonian-Laird remains the most widely used approach and an adequate method in most scenarios. ${ }^{5}$

Finally, Cella \& Preti raised two points about the way control conditions were handled in the review. We would like to reassure readers that we did not double-count studies by considering active control conditions for one analysis as active treatment conditions in another analysis. We further wish to clarify that treatment participants in all trials received the psychosocial intervention as an adjunct to treatment as usual (TAU), as doing otherwise would be considered unethical.

1 Higgins JP, Green S. Cochrane Handbook for Systematic Reviews of Interventions. John Wiley \& Sons, 2011.

2 Elis $\mathrm{O}$, Caponigro JM, Kring AM. Psychosocial treatments for negative symptoms in schizophrenia: current practices and future directions. Clin Psychol Rev 2013; 33: 914-28.

3 Fu R, Holmer HK. Change score or follow-up score? Choice of mean difference estimates could impact meta-analysis conclusions. J Clin Epidemiol 2016; 76: 108-17.

4 Cornell JE, Mulrow CD, Localio R, Stack CB, Meibohm AR, Guallar E, et al. Random-effects meta-analysis of inconsistent effects: a time for change. Ann Intern Med 2014; 160: 267-70.

5 DerSimonian R, Laird N. Meta-analysis in clinical trials revisited. Contemp Clin Trials 2015; 45(Pt A): 139-45.

Danyael Lutgens, MSc, Department of Psychiatry, McGill University, Douglas Menta Health University Institute, Montréal, Quebec; Genevieve Gariepy, PhD, McGill University, Institute for Health and Social Policy, Montréal, Quebec; Ashok Malla MD, FRCPC, MCGill University, Douglas Mental Health University Institute, Montréal, Quebec, Canada. Email: ashok.malla@mcgill.ca

doi: 10.1192/bjp.211.2.116a did not have autism according to the ADI-R. This instrument is not appropriate to making a sole diagnosis of autism in clinical practice. It not uncommonly misses high-functioning autism. In addition, Ventola et $a l^{3}$ have shown that the ADI-R was significantly 'under-diagnosing toddlers'. How biased and unrepresentative the patients in this survey can be seen by Professor Gillian Baird's work on autism in the general population. ${ }^{4}$ Indeed, using these narrow criteria gives a prevalence of autism of 25 per 10000 . When you use the broader autism spectrum, you get a truer rate of 116 per 10000 . One of the problems also is that the National Institute for Health and Care Excellence (NICE) guidelines on the diagnosis of autism, ${ }^{5}$ which are accepted throughout the world, are not followed. These state that there is no specific instrument recommended for diagnosis of autism and that identification depends on a clinical diagnosis by an experienced clinician. Dorothy Bishop, Professor of Developmental Neuropsychology at the University of Cambridge, told Adam Feinstein that, 'If it could be shown that there were real benefits in accuracy of diagnosis from adopting this lengthy procedure, then I'd be happy to say: "Okay". But the originators of the instrument have never demonstrated [this] - it is really more an article of faith with them. ${ }^{6}$ Feinstein also reports that, at the prestigious International Meeting for Autism in London in 2009, senior autism researchers 'lambasted' these narrow instruments 'for missing many cases of autism'.

1 Larson FV, Wagner AP, Jones PB, Tantam D, Meng-Chuan L, Baron-Cohen S, et al. Psychosis in autism: comparison of the features of both conditions in a dually affected cohort. Br J Psychiatry 2017; 210: 269-75.

2 Fitzgerald M. Schizophrenia and autism/Aspergers syndrome: overlap and difference. Clin Neuropsychiatry 2012; 9: 171-6.

3 Ventola PE, Kleinman J, Pandey P, Barton M, Allen S, Greene J, et al. Agreement among four diagnostic instruments for autism spectrum disorders in toddlers. J Autism Dev Disord 2006; 36: 839-47.

4 Baird G, Simonoff E, Pickles A, Chandler S, Loucast Meldrum D, Charman T. Prevalence of disorders of the autism spectrum disorder in a population cohort of children in South Thames: the Special Needs and Autism Project. Lancet 2006; 368: 210-5.

5 National Institute for Health and Care Excellence. Autism: Recognition, Referral, Diagnosis and Management of Adults on the Autism Spectrum. British Psychological Society \& Royal College of Psychiatrists, 2012.

6 Feinstein A. A History of Autism. Wiley-Blackwell, 2010.

Michael Fitzgerald, Psychiatrist and Adjunct Professor of Psychiatry, Department of Psychiatry, Trinity College Dublin. Email: profmichaelfitzgerald@gmail.com

doi: 10.1192/bjp.211.2.117

\section{The clinical utility of the ADI-R and ADOS in diagnosing autism}

Larson et $a l^{1}$ report on a major study on psychosis in autism, which is an important topic. ${ }^{2}$ They point out that their sample is non-representative, but then use the Autism Diagnostic Interview-Revised (ADI-R) and Autism Diagnostic Observation Schedule (ADOS) for clinical diagnosis. This vastly increases the non-representativeness of the sample unnecessarily and takes it a very long way away from autism in the general population. The criteria they used to define autism are very narrow concepts of the disorder. Clinical diagnoses based on this narrow view tell us very little about autism as seen in routine clinical practice, where professionals throughout the world now accept that the broader autism phenotype. I see many parents who come to me in great distress knowing that their child has autism and that the school also observed this, but having been told that their child
Author's reply: Professor Fitzgerald comments on the 'real-life' utility of the ADI-R and ADOS. It is his view that this may have limited the representativeness of our sample with respect to the autistic presentation. However, the ADI-R or ADOS were used only for inclusion/exclusion when we were referred participants who did not have an existing clinical diagnosis of autism spectrum disorder (ASD). This was a small number of participants $(n=19)$, and the number who were excluded because they did not meet cut-offs was even smaller $(n=8)$. It is interesting to note that our experience actually supports Fitzgerald's observations, in that participants in the research did differ significantly from a comparison sample of people with ASD in terms of their ADI-R scores, as discussed in our article. ${ }^{1}$

The wider question alluded to in Fitzgerald's letter is one of categorical diagnoses and the utility of boundaries. Obviously, 